\title{
Investigation of Thermophysical Properties of Nanomagnetite-based Polymer Materials
}

\author{
Ekaterina L. Kuznetsova ${ }^{1}$, Minggong Sha ${ }^{2}$, \\ ${ }^{1}$ Moscow Aviation Institute (National Research University), \\ Moscow, Volokolamskoe shosse, 4, 125993, \\ Russia \\ ${ }^{2}$ School of Civil Aviation, Northwestern Polytechnical University (NPU), \\ Xi'an Shaanxi, 127 West Youyi Road, Beilin District, 710072,
}

China

Received: March 15, 2021. Received: September 1, 2021. Accepted: September 21, 2021. Published: September 27, 2021.

\begin{abstract}
In this work, samples of magnetite nanoparticles are synthesized using various synthetic methods. It is shown that of the existing methods of magnetite synthesis, the most widespread is the method of coprecipitation of $\mathrm{Fe}^{2+}$ and $\mathrm{Fe}^{3+}$ salts. Less common, but of interest due to the slower and more controlled kinetics of particle nucleation, is the $\mathrm{Fe}^{2+}$ oxidation method. However, magnetite is unstable and under external influences its phase transition to maghemite can occur, which leads to a change in magnetic characteristics and a change in biological responses. After analyzing the results of the study of samples by the XRD method, the following conclusions can be drawn: The magnetite phase was identified by the characteristic peaks in the diffraction patterns for all samples, except for the sample with EDTA, which may be a consequence of an insufficient amount of the introduced oxidant, or poor diffusion of the oxidant to iron ions due to the formed chelate complex. It can be concluded that magnetite is a promising material for its use in industry and medicine.
\end{abstract}

Keywords-Nanoparticles, magnetite, polymers, mechanical properties.

\section{INTRODUCTION}

C URRENTLY, much attention is paid to the field of nanotechnology, which is one of the most promising and rapidly developing. A large number of works are underway to study the use of magnetic nanoparticles in various fields, including industry and medicine [1]-[12]. Most of the applied magnetic nanoparticles are iron oxide nanoparticles, namely magnetite $\mathrm{Fe}_{3} \mathrm{O}_{4}$. Among the methods for obtaining magnetite nanoparticles, liquid-phase methods are mainly used, which are much easier to perform and require less energy and economic costs [13]-[24]. Among them, the most common method: the method of coprecipitation of iron salts (II, III). The advantages of the method include the rapidity of synthesis due to the rapid nucleation of nanoparticles, the ease of synthesis due to one-stage mixing of salts in an alkaline medium, a high yield of the target product due to the complete conversion of the starting components, as well as the possibility of differentiation of the morphology and composition of nanoparticles at the synthesis stage [25]-[41]. However, despite the indicated advantages, this method also has a number of disadvantages. The main problems in the rapid nucleation of nanoparticles are the problem of separation of nucleation and growth of nanoparticles, as well as the problem of the need to control after nucleation over the growth processes of monodisperse nanoparticles, which are reflected in the uniformity of nanoparticle size distribution.

Coatings on nano and micro-sized particles can serve for many purposes. First of all, modification of the surface with coatings makes it possible to make the particles compatible with various matrixes [42]-[68]. For medical purposes, the biocompatibility with the environments of a living organism is of crucial importance. It is equally important that coatings can significantly enhance or decrease the sorption properties of magnetically controlled sorbents. This provides prerequisites for the creation of magnetically controlled particles with specific sorption properties. It is also known that the coatings prevent the core from leaching out. The presence of a coating also often facilitates the stabilization of particles in an environment with an alkaline $\mathrm{pH}$ or significant salt concentration. For example, the isoelectric point of $\mathrm{SiO}_{2}$ is reached at $\mathrm{pH} 2-3$. Therefore, the particles coated with silica are negatively charged at the $\mathrm{pH}$ of the blood, which causes 
electrostatic repulsion, which avoids the formation of clumps.

There are several ways to synthesize composite nanoparticles [25]-[41].

Modern composites have not only a wide range of physical and mechanical properties, but are also capable of directionally changing them, for example, increasing fracture toughness, regulating rigidity, strength, and other properties. These possibilities are expanded when fibers of different nature and geometry are used in composites, i.e., when creating hybrid composites. In addition, these materials are characterized by the appearance of a synergistic effect (coordinated joint action of several factors in one direction) [31]-[47].

The properties of the interface or interfacial zone, first of all, the adhesive interaction between the fiber and the matrix, determine the level of properties of composites and their retention during operation. Local stresses in the composite reach their maximum values just near or directly at the interface, where material destruction usually begins. The interface must have certain properties to ensure efficient transfer of the mechanical load from the matrix to the fiber. The adhesion bond at the interface should not be destroyed under the action of thermal and shrinkage stresses arising from the difference in the temperature coefficients of linear expansion of the matrix and fiber or as a result of chemical shrinkage of the binder during its curing.

When creating nanocomposites, the key tasks are the development of efficient, reliable, and affordable production technologies for mass production, which make it possible to obtain materials with stable characteristics. The hand lay technique, also called wet lay, is the simplest and most widely used process for producing flat reinforced composites. The process consists of laying layers of a polymer in successive layering using an epoxy matrix. Wet-laying is a molding process that combines layers of reinforced carbon fiber with epoxy to create a high-quality laminate. Before starting the installation process, you must prepare the appropriate form. This preparation consists of cleaning the table and applying a release agent to the surface. The manual laying process can be divided into four main steps: mold preparation, epoxy coating, laying and curing. Form preparation is one of the most important steps in the installation process. This process requires dry reinforcement layers and the application of a wet epoxy matrix. They are connected together - reinforcing material, impregnated with a matrix

Nanoparticles, even with a very low volumetric content (less than $1 \%$ ), are contained in such a fragment in a very large amount, and it is impossible to model their effect at this scale level. For example, a cubic fragment of a $1 \mu \mathrm{m}$ matrix contains more than thousand nanoparticles for a given volumetric content. Therefore, in particular, the nano-modified binder is white, while the usual binder is yellow. To model such materials, it is necessary to resort to multiscale approaches and to carry out a consistent determination of effective properties at various scale levels. This task is greatly simplified if the properties of the nanomodified matrix are known from experiments. The missing characteristic is Poisson's ratio, which can be approximately taken unchanged, or estimated on the basis of analytical calculations using the found value of the "effective" volumetric content of the filler, which was done. Further, it suffices to numerically solve the averaging problem on a representative fragment containing only nanoparticles.

In order to derive the equation of the adsorption isotherm, a number of simplifications are introduced. All the places where the adsorbed particles are fixed are the same, and adsorption on one of them does not affect the state of the other. The interaction between the adsorbed particles is negligible. The adsorption layer is monomolecular, i.e. it consists of one layer of molecules. In this case, the bond of the adsorbate with the adsorbent is sufficiently strong, which excludes the movement of the adsorption complex along the surface of the adsorbent (localized adsorption).

Active (well absorbing) adsorbents have a very large specific surface area. For example, the absorbers most often used for scientific purposes and industrial practice - activated carbon, silica gel, zeolites - have $\mathrm{s}_{0}$ up to several hundred and even thousands of square meters per $1 \mathrm{~g}$.

The ability of the adsorbent to absorb the adsorbate is characterized by the amount of adsorption. The amount of adsorption is the excess mass of the adsorbate in the boundary layer over its mass in an equal volume of the environment, referred to the unit surface of the adsorbent.

Sometimes the adsorption value is expressed in moles of adsorbate per $1 \mathrm{~m}^{2}$ (or $1 \mathrm{~cm}^{2}$ ) of the adsorbent surface. Since quite often the surface of the adsorbent is unknown, the value of adsorption is expressed in moles of adsorbate per $1 \mathrm{~g}$ of adsorbent $(\mathrm{mol} / \mathrm{g})$. It is customary to evaluate the process of toxin sorption by the adsorbing surface using the curves of Langmuir sorption isotherms.

Silanol binding agents are applied directly to the surface of $\mathrm{Fe}_{3} \mathrm{O}_{4}$ nanoparticles by copolymerization of monomers or by direct silanization. The developed surface of nanoparticles leads to a high density of surface functional groups [48]-[57], which can fix a large number of biologically active substances [32]. The most common way to obtain $\mathrm{LF} \mathrm{Fe}_{3} \mathrm{O}_{4} / \mathrm{SiO}_{2}$ with a core-shell structure is the sol-gel method (Stober method), which consists in hydrolysis and polycondensation under alkaline conditions in ethanol [33].

\section{SYNTHESIS OF THE MAGNETITE NANOPARTICLES}

One of the main characteristics that magnetite nanoparticles used in immunoassay and clinical diagnostics should possess today is a narrow nanoparticle size distribution. To obtain monodisperse magnetite particles, it is necessary to separate the process of ion nucleation in solution and the growth of particle crystals. Thus, the coprecipitation method allows one to obtain nanoparticles with a rather wide size distribution (coefficient of variation of sizes $>20 \%$ ). 
Table 1. List of obtained samples of magnetite nanoparticles.

\begin{tabular}{|l|l|}
\hline Sample & Sample description \\
\hline $\mathrm{M}-\mathrm{E}$ & $\begin{array}{l}\text { Synthesis of magnetite from FeSO4} \cdot 7 \mathrm{H} 2 \mathrm{O} \\
\text { and EDTA at room temperature }\end{array}$ \\
\hline $\mathrm{M}-\mathrm{X}$ & Synthesis of magnetite from $\mathrm{FeCl} 2$ \\
\hline $\mathrm{M}-$ & $\mathrm{Synthesis} \mathrm{of} \mathrm{magnetite} \mathrm{from}^{\mathrm{FeSO}} \cdot\left(\mathrm{NH}_{4}\right)_{2} \mathrm{SO}_{4} \cdot 6 \mathrm{H}_{2} \mathrm{O}$ \\
\hline M - C & $\begin{array}{l}\text { Synthesis of magnetite from } \mathrm{FeCl} 3 \cdot 6 \mathrm{H} 2 \mathrm{O} \text { и } \\
\text { FeCl2 } \cdot 4 \mathrm{H} 2 \mathrm{O}\end{array}$ \\
\hline
\end{tabular}

Table 1 gives the overview of the synthesized samples of nanoparticles with different conditions of synthesis.

\section{RESULTS AND DISCUSSION}

To study the phase and microstructural characteristics, an X-ray phase analysis was carried out. 3 samples were studied: $\mathrm{M}-\mathrm{E}, \mathrm{M}-\mathrm{CM}, \mathrm{M}-\mathrm{C}$. The sizes of the regions of coherent scattering of X-rays corresponding to the sizes of nanoparticles were determined by the Scherrer formula.

Consider the diffraction pattern of the M - E sample shown in Figure 1.

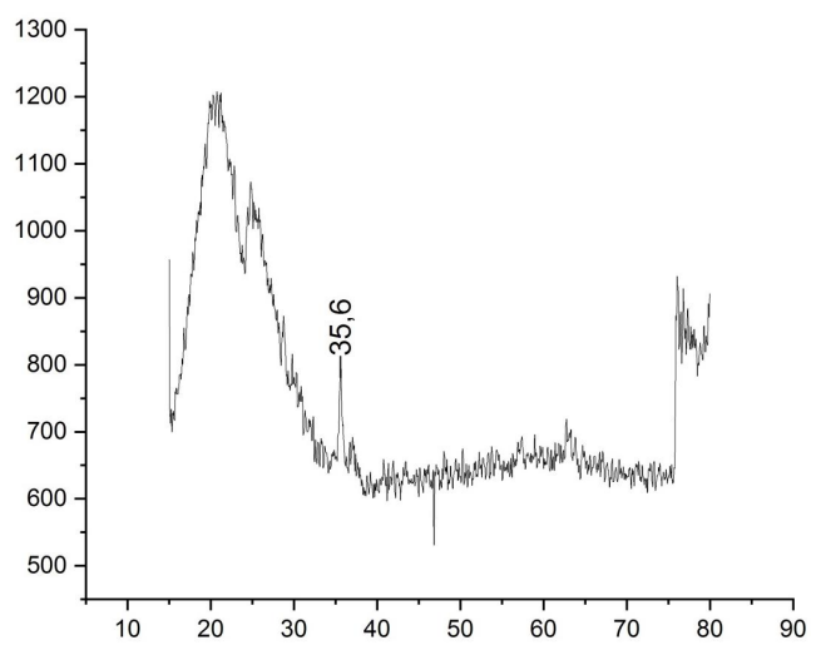

Fig. 1 Diffraction pattern of sample M - C in coordinates intensity - two theta.

Sample M - E was obtained by oxidation of $\mathrm{Fe}^{2+}$ from a complex with EDTA at room temperature. The diffractogram for this sample shows one peak $(2 \theta=35)$, which is characteristic of the magnetite phase, but the other peaks are absent. On this basis, it can be said that the crystal structure of magnetite was not formed during the synthesis. This may be due to an insufficient amount of an oxidizing agent, or to a weak diffusion of an oxidizing agent to $\mathrm{Fe}^{2+}$ ions due to a too strong steric barrier formed by EDTA.

The diffractogram of the M - C sample obtained by coprecipitation of iron (II, III) chlorides is shown in Figure 2.
The peaks in the diffractogram of the sample were identified as belonging to the magnetite phase.

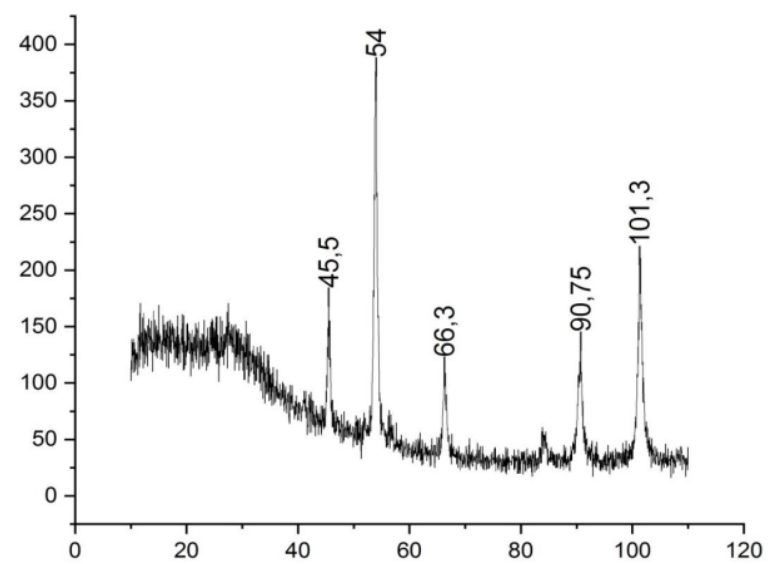

Fig. 2 Diffraction pattern of sample $\mathrm{M}-\mathrm{C}$ in coordinates intensity - two theta.

XRD results for sample $\mathrm{M}-\mathrm{C}$ and calculations of the stoichiometric composition showed that the sample is dominated by the magnetite phase (93\%).

Also, for sample $\mathrm{M}-\mathrm{C}$, according to the results of XRD, a histogram of the particle size distribution was plotted, shown in Figure 3. Analyzing the histogram of the particle size distribution, it can be concluded that the particles are unevenly distributed, that is, there is a polymodal distribution.

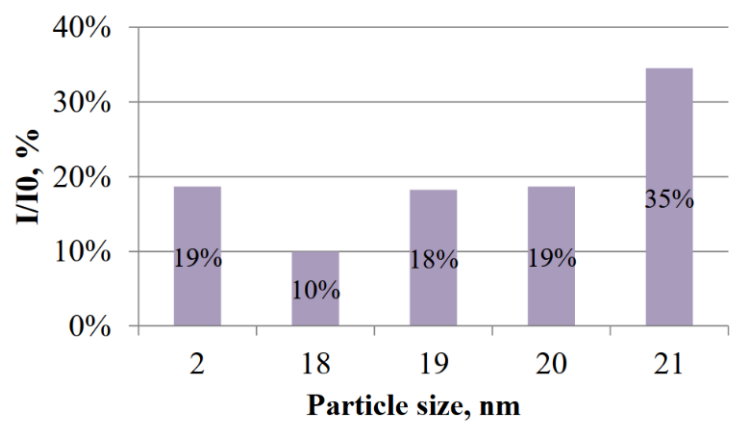

Fig. 3 Histogram of particle size distribution in sample M - C.

The diffractogram of sample $\mathrm{M}-\mathrm{X}$ is shown in Fig. 4, it clearly shows resonance peaks characteristic of magnetite. 


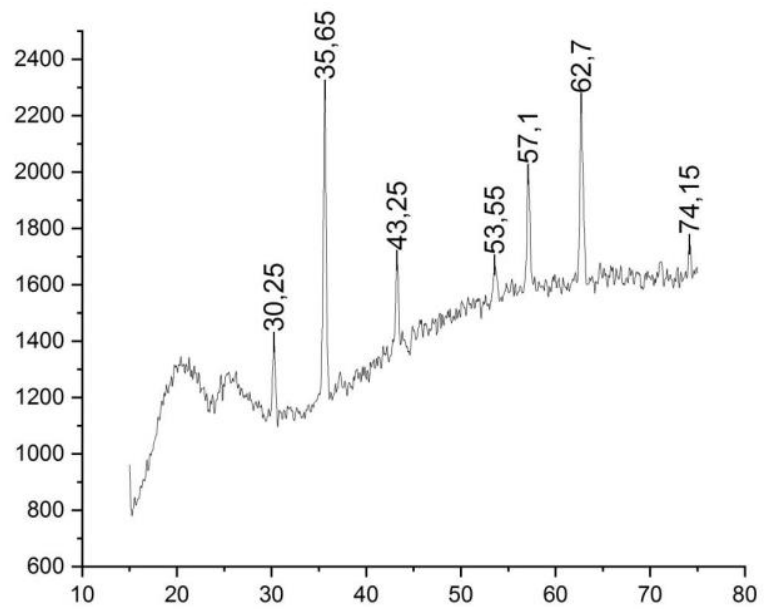

Fig. 4 Diffraction pattern of sample $\mathrm{M}-\mathrm{X}$ in coordinates intensity - two theta.

The XRD results show that the phase composition of stoichiometric magnetite is even lower than that of the M - C sample, which may be due to the insufficient amount of the introduced oxidant. This results in the lack of the oxygen in the reacting system and so affects the stoichiometry of the magnetite.

On the histogram of the particle size distribution plotted for the M - X sample, shown in Figure 5, you can see a large percentage of particles of practically the same size $25-26 \mathrm{~nm}$, that is, the distribution is bimodal.

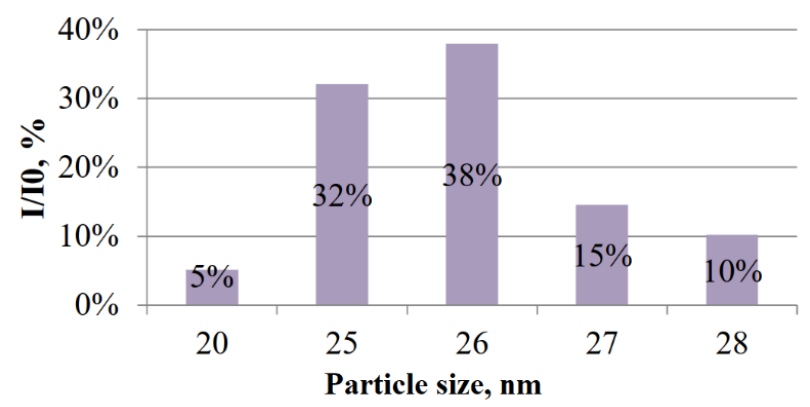

Fig. 5 Histogram of the distribution of particles in the sample M$\mathrm{X}$.

The M - CM sample was also studied by XRD. Its diffractogram is shown in Figure 6, in which the resonance peaks are identified as corresponding to the magnetite phase.

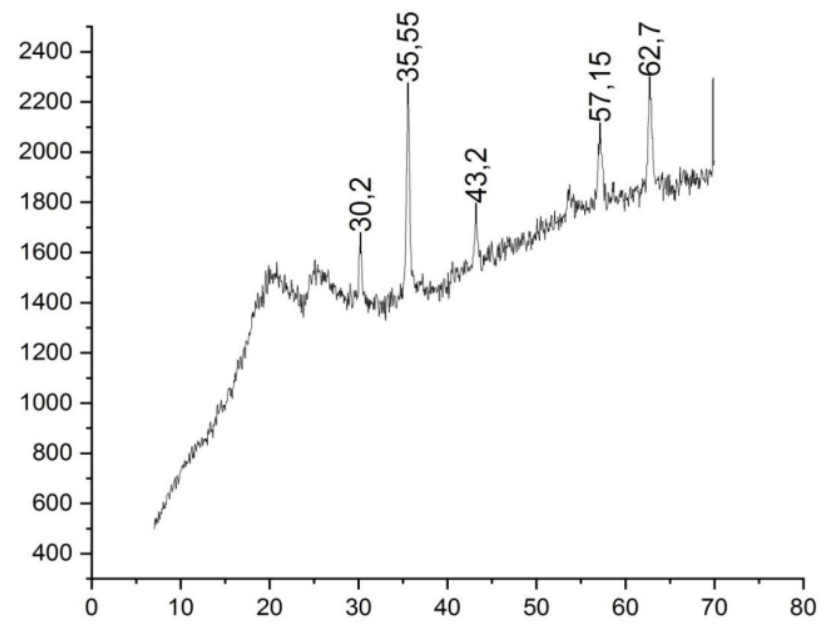

Fig. 6 Diffraction pattern of sample $\mathrm{M}-\mathrm{CM}$ in coordinates intensity - two theta.

According to the XRD data for the M - CM sample, it can be noted that even less percentage of stoichiometric magnetite $(88 \%)$ is observed in the composition of particles than in the previous two samples, which may be a consequence of either an insufficient amount of the introduced oxidant, or hindered diffusion of the oxidant to $\mathrm{Fe}^{2+}$ ions due to the steric structure of the Mohr salt chelate complex.

Based on these data, a histogram of the particle size distribution was built, shown in Figure 7. More than half of the particles were of the same size equal to $23 \mathrm{~nm}$, that is, a monomodal distribution was observed.

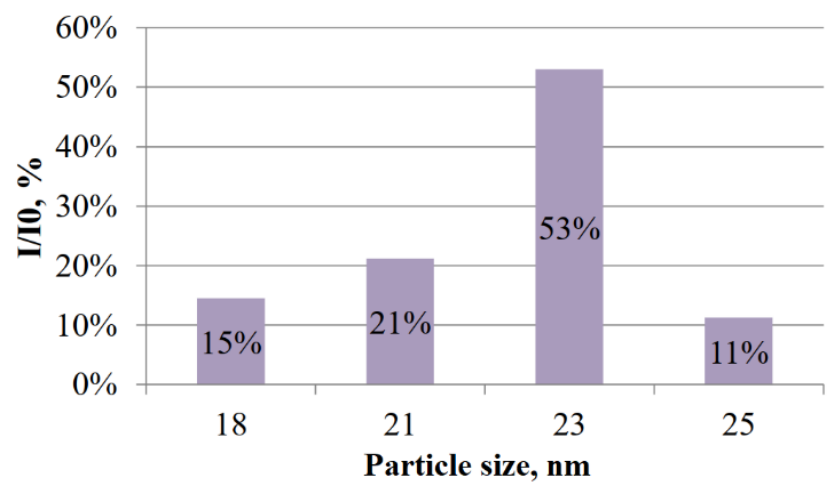

Fig. 7 Histogram of the particles distribution in the sample M-CM.

Thus, the synthesis by the oxidation of iron ions from a complex with a higher binding constant, compared to the binding constant of $\mathrm{FeCl}_{2}$, actually allows one to obtain particles with a monomodal size distribution. This result demonstrates that the synthesis of magnetite from $\mathrm{FeSO}_{4} \cdot\left(\mathrm{NH}_{4}\right)_{2} \mathrm{SO}_{4} \cdot 6 \mathrm{H}_{2} \mathrm{O}$ if favorable in view of homogeneity and allows to obtain high quality nanoparticles.

\section{CONCLUSION}

After analyzing the results of the study of samples by the XRD method, the following conclusions can be drawn: The magnetite phase was identified by the characteristic peaks in the diffraction patterns for all samples, except for the sample 
with EDTA, which may be a consequence of an insufficient amount of the introduced oxidant, or poor diffusion of the oxidant to iron ions due to the formed chelate complex; the closest to stoichiometric magnetite was the calculated composition of sample $\mathrm{M}$ - C, equal to $93 \%$, for sample $\mathrm{M}$ - X this figure was $91 \%$, and for sample $\mathrm{M}$ - CM 88\%; sample M $\mathrm{C}$ had a polymodal particle size distribution, sample $\mathrm{M}-\mathrm{X}$ bimodal, and sample $\mathrm{M}$ - CM monomodal, which may indicate the effect of the binding force (complexation constant values) on the kinetics of nanoparticle formation, that is, on the dispersion of the resulting particles by size.

This opens new prospective for tailored fabrication of polymer nanocomposites with desired structure and properties. Further research can be aimed toward the development of nanocomposites with advanced mechanical properties.

To determine the structure of the obtained nanocomposite, the method of IR spectroscopy was used. IR spectroscopy allows first to get evidences of the interaction between nanoparticles and polymer matrix and, second, get the information about the structure of the resulting nanocomposite. For the details of the IR characterization of the polymer nanocomposites, it is referred to the literature [53]-[55].

\section{ACKNOWLEDGEMENT}

This study was funded by RFBR, project number 20-0100523 .

\section{REFERENCES}

[1] L. N. Rabinskiy, S. A. Sitnikov, "Development of technologies for obtaining composite material based on silicone binder for its further use in space electric rocket engines," Periodico Tche Quimica, 15(Special Issue 1), pp. 390-395, 2018.

[2] P. F. Pronina, O. V. Tushavina, E. I. Starovoitov, "Study of the radiation situation in moscow by investigating elastoplastic bodies in a neutron flux taking into account thermal effects," Periodico Tche Quimica, 17(35), pp. 753-764, 2020.

[3] A. A. Orekhov, Y. A. Utkin, P. F. Pronina, "Determination of deformation in mesh composite structure under the action of compressive loads," Periodico Tche Quimica, 17(35), pp. 599-608, 2020.

[4] A. V. Babaytsev, L. N. Rabinskiy, K. T. Aung, "Investigation of the contact zone of a cylindrical shell located between two parallel rigid plates with a gap," INCAS Bulletin, 12(Special Issue), pp. 43-52, 2020.

[5] O. A. Pashkov, "Influence of Polymer Coatings on the Mechanical Properties of Steel Samples in Tensile and Bending Tests," Turkish Journal of Computer and Mathematics Education (TURCOMAT), vol. 12, no. 5, pp. 542-548, 2021.

[6] O. A. Pashkov, "Investigation of the Effect of Steel Plate Size and Elevated Temperature on Critical Load in Stability Tests," Turkish Journal of Computer and Mathematics Education (TURCOMAT), vol. 12, no. 10, pp. 1657-1663, 2021.
[7] Y. Sun, O. V. Egorova, E. L. Kuznetsova, "Identification of the front angle of a plane acoustic oblique pressure wave on convex surfaces with the use of analytical solution," Journal of the Balkan Tribological Association, 27(2), pp. 189-197, 2021.

[8] N. A. Kucheva, V. Kohlert, "Mathematical modeling methods for estimation the thermophysical properties of heat-protective composite materials," Turkish Journal of Computer and Mathematics Education (TURCOMAT), vol. 12, no. 10, pp. 1606-1612, 2021.

[9] V. G. Dmitriev, O. V. Egorova, E. I. Starovoitov, "Particularities of mathematical modeling of deformation processes for arched and panel designs of composites with large displacements and rotation angles," INCAS Bulletin, 12(Special Issue), pp. 53-66, 2020.

[10] O. V. Egorova, E. I. Starovoitov, "Non-stationary diffraction problem of a plane oblique pressure wave on the shell in the form of a hyperbolic cylinder taking into account the dissipation effect," INCAS Bulletin, 12(Special Issue), pp. 67-77, 2020.

[11]O. V. Tushavina, "Coupled heat transfer between a viscous shock gasdynamic layer and a transversely streamlined anisotropic half-space," INCAS Bulletin, 12 (Special Issue), pp. 211-220, 2020.

[12] S. Vakhneev, E. Starovoitov, "Damping of circular composite viscoelastic plate vibration under neutron irradiation," Journal of Applied Engineering Science, 18(4), pp. 699-704, 2020.

[13] V. A. Pogodin, L. N. Rabinskii, S. A. Sitnikov, "3D Printing of Components for the Gas-Discharge Chamber of Electric Rocket Engines," Russian Engineering Research, vol. 39, no. 9, pp. 797-799, 2019.

[14] V. F. Formalev, S. A. Kolesnik, B. A. Garibyan, "Mathematical modeling of heat transfer in anisotropic plate with internal sinks," AIP Conference Proceedings, 2181, 020003, 2019.

[15] O. A. Pashkov, "Theoretical calculation of the thickness of interphase zones in the Al-Al2O3 composite," Turkish Journal of Computer and Mathematics Education (TURCOMAT), vol. 12, no. 10, pp. 1672-1677, 2021.

[16] O. A. Pashkov, "Experimental and Theoretical Study of Mechanical Properties of Matrix Composite Materials," Turkish Journal of Computer and Mathematics Education (TURCOMAT), vol. 12, no. 10, pp. 1678-1684, 2021.

[17] V. F. Formalev, S. A. Kolesnik, B. A. Garibyan, "Heat transfer with absorption in anisotropic thermal protection of high-temperature products," Herald of the Bauman Moscow State Technical University, Series Natural Sciences, (5), pp. 35-49, 2019.

[18] V. F. Formalev, S. A. Kolesnik, B. A. Garibyan, "Analytical solution of the problem of conjugate heat transfer between a gasdynamic boundary layer and anisotropic strip," Herald of the Bauman Moscow State Technical University, Series Natural Sciences, 5(92), pp. 44-59.

[19]I. Kurchatov, N. Bulychev, S. Kolesnik, E. Muravev, "Application of the direct matrix analysis method for calculating the parameters of the luminescence spectra of 
the iron ion in zinc sulfide crystals," AIP Conference Proceedings, 2181, 020015, 2019.

[20]O. A. Butusova, "Surface Modification of Titanium Dioxide Microparticles Under Ultrasonic Treatment," International Journal of Pharmaceutical Research, vol. 12, i. 4, pp. 2292-2296, 2020.

[21] O. A. Butusova, "Stabilization of Carbon Microparticles by High-Molecular Surfactants," International Journal of Pharmaceutical Research, vol. 12, Supplementary Issue 2, pp. 1147-1151, 2020.

[22] Yu. V. Ioni, A. Ethiraj, "New Tailor-Made Polymer Stabilizers for Aqueous Dispersions of Hydrophobic Carbon Nanoparticles," International Journal of Pharmaceutical Research, vol. 12, i. 4, pp. 3443-3446, 2020.

[23] Yu. V. Ioni, "Nanoparticles of noble metals on the surface of graphene flakes," Periodico Tche Quimica, vol. 17, no. 36, pp. 1199-1211, 2020.

[24] O. A. Butusova, "Vinyl Ether Copolymers as Stabilizers of Carbon Black Suspensions," International Journal of Pharmaceutical Research, vol. 12, Supplementary Issue 2, pp. 1152-1155, 2020.

[25] M. O. Kaptakov, "Catalytic Desulfuration of Oil Products under Ultrasonic Treatment," International Journal of Pharmaceutical Research, vol. 12, Supplementary Issue 2, pp. 1838-1843, 2020.

[26]B. A. Garibyan, "Enhancement of Mechanical Properties of Inorganic Glass under Ultrasonic Treatment," International Journal of Pharmaceutical Research, vol. 12, Supplementary Issue 2, pp. 1829-1832, 2020.

[27]M. O. Kaptakov, "Enhancement of Quality of Oil Products under Ultrasonic Treatment," International Journal of Pharmaceutical Research, vol. 12, Supplementary Issue 2, pp. 1851-1855, 2020.

[28] O. A. Butusova, "Adsorption Behaviour of Ethylhydroxyethyl Cellulose on the Surface of Microparticles of Titanium and Ferrous Oxides," International Journal of Pharmaceutical Research, vol. 12, Supplementary Issue 2, pp. 1156-1159, 2020.

[29]A. N. Tarasova, "Vibration-based Method for Mechanochemical Coating Metallic Surfaces," International Journal of Pharmaceutical Research, vol. 12, Supplementary Issue 2, pp. 1160-1168, 2020.

[30]B. A. Garibyan, "Mechanical Properties of Electroconductive Ceramics," International Journal of Pharmaceutical Research, vol. 12, Supplementary Issue 2, pp. 1825-1828, 2020.

[31]M. O. Kaptakov, "Effect of Ultrasonic Treatment on Stability of $\mathrm{TiO}_{2}$ Aqueous Dispersions in Presence of Water-Soluble Polymers," International Journal of Pharmaceutical Research, vol. 12, Supplementary Issue 2, pp. 1821-1824, 2020.

[32] Yu. V. Ioni, "Synthesis of Metal Oxide Nanoparticles and Formation of Nanostructured Layers on Surfaces under Ultrasonic Vibrations," International Journal of Pharmaceutical Research, vol. 12, i. 4, pp. 3432-3435, 2020.
[33] A. N. Tarasova, "Effect of Reagent Concentrations on Equilibria in Water-Soluble Complexes," International Journal of Pharmaceutical Research, vol. 12, Supplementary Issue 2, pp. 1169-1172, 2020.

[34]A. N. Tarasova, "Effect of Vibration on Physical Properties of Polymeric Latexes," International Journal of Pharmaceutical Research, vol. 12, Supplementary Issue 2, pp. 1173-1180, 2020.

[35] Yu. V. Ioni, A. Ethiraj, "Study of Microparticles Surface Modification by Electrokinetic Potential Measuring," International Journal of Pharmaceutical Research, vol. 12, i. 4, pp. 3436-3439, 2020.

[36] Yu. V. Ioni, "Effect of Ultrasonic Treatment on Properties of Aqueous Dispersions of Inorganic and Organic Particles in Presence of Water-Soluble Polymers," International Journal of Pharmaceutical Research, vol. 12, i. 4, pp. 3440-3442, 2020.

[37] N. A. Kucheva, "Investigation of the mechanical properties of heat-protective highly porous composite materials using the effective medium model," Turkish Journal of Computer and Mathematics Education (TURCOMAT), vol. 12, no. 10, pp. 1613-1621, 2021.

[38] N. A. Kucheva, V. Kohlert, "Analytical solution of the problem of thermoelasticity for a plate heated by a source with a constant heat supply on one surface," Turkish Journal of Computer and Mathematics Education (TURCOMAT), vol. 12, no. 10, pp. 1622-1633, 2021.

[39]L. N. Rabinskiy, O. V. Tushavina, "Problems of land reclamation and heat protection of biological objects against contamination by the aviation and rocket launch site," Journal of Environmental Management and Tourism, 10(5), pp. 967-973, 2019.

[40] A. N. Astapov, I. P. Lifanov, L. N. Rabinskiy, "Perspective Heat-Resistant Coating for Protection of $\mathrm{Cf} / \mathrm{SiC}$ Composites in Air Plasma Hypersonic Flow," High Temperature, 57(5), pp. 744-752, 2019.

[41]O. A. Butusova, "Design and Properties of Magnetically Controlled Sorbents," Turkish Journal of Computer and Mathematics Education (TURCOMAT), vol. 12, no. 5, pp. 515-519, 2021.

[42] O. A. Butusova, "Application of Magnetically Controlled Sorbents for Detoxication," Turkish Journal of Computer and Mathematics Education (TURCOMAT), vol. 12, no. 5, pp. 520-524, 2021.

[43] V. N. Dobryanskiy, L. N. Rabinskiy, O. V. Tushavina, "Validation of methodology for modeling effects of loss of stability in thin-walled parts manufactured using SLM technology," Periodico Tche Quimica, 16(33), pp. 650656, 2019.

[44]M. O. Kaptakov, "Effect of Thin Polymer Layers on Mechanical Properties of Metal Surfaces," Turkish Journal of Computer and Mathematics Education (TURCOMAT), vol. 12, no. 5, pp. 525-529, 2021.

[45]B. A. Garibyan, "Determination of the Elastic Modulus of the Coating Using a Spherical Indenter," Turkish Journal of Computer and Mathematics Education (TURCOMAT), vol. 12, no. 10, pp. 1594-1600, 2021. 
[46] N. A. Bulychev, L. N. Rabinskiy, O. V. Tushavina, "Effect of intense mechanical vibration of ultrasonic frequency on thermal unstable low-temperature plasma," Nanoscience and Technology: An International Journal, 11 (1), pp. 15-21, 2020.

[47] M. O. Kaptakov, "Modelling of Mechanical Properties of Metal Plates with Polymer Coatings," Turkish Journal of Computer and Mathematics Education (TURCOMAT), vol. 12, no. 5, pp. 530-534, 2021.

[48]B. A. Garibyan, "Theoretical Estimations of Influence of Polymer Coatings on the Elastic Modulus and Ultimate Strength of Steel Samples," Turkish Journal of Computer and Mathematics Education (TURCOMAT), vol. 12, no. 10, pp. 1651-1656, 2021.

[49] M. O. Kaptakov, "Investigation of Effective Mechanical Characteristics of Nanomodified Carbon-Epoxide Composite by Numerical and Analytical Methods," Turkish Journal of Computer and Mathematics Education (TURCOMAT), vol. 12, no. 5, pp. 535-541, 2021.

[50] M. O. Kaptakov, "Obtaining of Carbon Fibers Based Composite Materials and Study of Their Mechanical Properties," Turkish Journal of Computer and Mathematics Education (TURCOMAT), vol. 12, no. 10, pp. 1601-1605, 2021.

[51]Y. K. Kyaw, P. F. Pronina, P. O. Polyakov, "Mathematical modelling of the effect of heat fluxes from external sources on the surface of spacecraft," Journal of Applied Engineering Science, 18(4), pp. 732-736, 2020.

[52] N. A. Bulychev, A. V. Ivanov, "Effect of vibration on structure and properties of polymeric membranes," International Journal of Nanotechnology, vol. 16, nos. 6/7/8/9/10, pp. $334-343,2019$.

[53] N. A. Bulychev, A. V. Ivanov, "Nanostructure of OrganicInorganic Composite Materials Based on Polymer Hydrogels," International Journal of Nanotechnology, vol. 16, nos. 6/7/8/9/10, pp. $344-355,2019$.

[54] N. A. Bulychev, A. V. Ivanov, "Study of Nanostructure of Polymer Adsorption Layers on the Particles Surface of Titanium Dioxide," International Journal of Nanotechnology, vol. 16, nos. 6/7/8/9/10, pp. 356 - 365, 2019.

[55]A. N. Astapov, I. P. Lifanov, M. V. Prokofiev, "Hightemperature interaction in the $\mathrm{ZrSi} 2-\mathrm{ZrSiO} 4$ system and its mechanism," Russian Metallurgy (Metally), no. 6, pp. $640-646,2019$.

[56] N. A. Bulychev, L. N. Rabinskiy, O. V. Tushavina, "Effect of intense mechanical vibration of ultrasonic frequency on thermal unstable low-temperature plasma," Nanoscience and Technology: An International Journal, 11 (1), pp. 15-21, 2020.

[57]N. A. Bulychev, L. N. Rabinskiy, "Ceramic Nanostructures Obtained by Acoustoplasma Technique," Nanoscience and Technology: An International Journal, 10 (3), pp. 279-286, 2019.

[58]N. A. Bulychev, E. L. Kuznetsova, "Ultrasonic Application of Nanostructured Coatings on Metals," Russian Engineering Research, 39 (9), pp. 809-812, 2019.
[59]N. A. Bulychev, V. V. Bodryshev, L. N. Rabinskiy, "Analysis of geometric characteristics of two-phase polymer-solvent systems during the separation of solutions according to the intensity of the image of micrographs," Periodico Tche Quimica, 16(32), pp. 551$559,2019$.

[60] S. A. Kolesnik, N. A. Bulychev, "Numerical analytic method for solving the inverse coefficient problem of heat conduction in anisotropic half-space," Journal of Physics: Conference Series, 1474(1), 012024, 2020.

[61] V. F. Formalev, N. A. Bulychev, S. A. Kolesnik, M. A. Kazaryan, "Thermal state of the package of cooled gasdynamic microlasers," Proceedings of SPIE - The International Society for Optical Engineering, 11322, article number 113221B, 2019.

[62] G. A. Kalugina, A. V. Ryapukhin, "Impact of the 2020 Pandemic on Russian Aviation," Russian Engineering Research, vol. 41. no. 7, pp. 627-630, 2021.

[63]R. N. Zaripov, I. M. Murakaev, A. V. Ryapukhin, "Development of the Organization's Key Performance Indicators System in Order to Improve the Effectiveness of Its Human Capital and Risk Management," TEM Journal, vol. 10, no. 1, pp. 298-302, 2021.

[64]A. A. Kalugin, G. A. Kalugina, A. V. Ryapukhin, "Informational Support for the Sale of Passenger Aircraft," Russian Engineering Research, vol. 41, no. 2, pp. 183-187, 2021.

[65] R. N. Zaripov, I. M. Murakaev, S. V. Novikov, A. V. Ryapukhin, "Corporate Structure for Innovative Enterprises," Russian Engineering Research, vol. 40, no. 2, pp. 137-139, 2020.

[66]A. Y. Burova, "Concept of multistage discrete fourier transform without performing multiplications" Journal of Physics: Conference Series, vol. 1889, no. 2, 022003, 2021.

[67] A. Burova, "Reducing the Error of Digital Algorithms for Deductive Signal Processing Based on Their Multi-Stage Discrete Fourier Transform by the Difference Digital Filters," 22th International Conference on Digital Signal Processing and its Applications, DSPA 2020, no. 9213275, 2020.

[68] A. Y. Burova, "Minimization of asymmetry of thrust of dual-flow turbojet engines of airliner in accordance with the results of system analysis of thrust parameters," Asia Life Sciences, no. 2, pp. 629-643, 2019.

\section{Sources of Funding for Research Presented in a Scientific Article or Scientific Article Itself}

This study was funded by RFBR, project number 20-0100523.

\section{Creative Commons Attribution License $\mathbf{4 . 0}$ (Attribution 4.0 International, CC BY 4.0)}

This article is published under the terms of the Creative Commons Attribution License 4.0

https://creativecommons.org/licenses/by/4.0/deed.en US 